\title{
Incidence and predictors of under-five mortality in East Africa using multilevel Weibull regression modeling
}

\author{
Getayeneh Antehunegn Tesema* (D, Achamyeleh Birhanu Teshale and Zemenu Tadesse Tessema
}

\begin{abstract}
Background: In 2017, an estimated 5.3 million under-five children died annually in Sub-Saharan African countries, more than half of those deaths occurred in East Africa. Though East African countries share the huge burden of global under-five mortality, there is limited evidence on the incidence and predictors of under-five mortality. Therefore, this study investigated the incidence and predictors of under-five mortality in East Africa.

Methods: A community-based cross-sectional study was done based on the Demographic and Health Survey (DHS) data of 12 East African countries conducted from 2008 to 2019. A total weighted sample of 138,803 live births within 5 years preceding the survey were included for analysis. The Kaplan-Meier curve and Log-rank test were done to assess the children's survival experience across variable categories. The Global Schoenfeld residual test was employed for checking Proportional Hazard (PH) assumptions and it was violated ( $p$-value< 0.05$)$. Considering the hierarchical nature of DHS data, multilevel parametric survival models were fitted. Model comparison was made by AIC, deviance, and shape of the hazard function. Variables with a $p$-value of less than 0.2 in the bi-variable analysis were considered for the multivariable analysis. In the multilevel Weibull regression analysis, the Adjusted Hazard Ratio (AHR) with 95\% Confidence Interval (Cl) was reported to declare the significant predictors of under-five mortality.
\end{abstract}

Results: Under-five mortality rate in East Africa was 51.318 (95\% Cl: 51.311, 51.323) per 1000 live births. Babies born to mothers attained secondary education and above ( $A H R=0.83,95 \% \mathrm{Cl}: 0.75,0.91)$, being 2 nd -4 th birth order $(A H R=0.62,95 \% \mathrm{Cl}: 0.56,0.67), \geq 5$ th birth order (AHR $=0.68,95 \% \mathrm{Cl}: 0.61,0.76)$, health facility delivery (AHR $=0.87$, $95 \%$ Cl: $0.82,0.93), 1-3$ ANC visit (AHR $=0.61,95 \% \mathrm{Cl}: 0.54,0.68)$, births interval of $24-48$ months (AHR $=0.53,95 \%$ Cl: $0.50,0.57$ ), wanted pregnancy (AHR $=0.72,95 \% \mathrm{Cl}: 0.68,0.76$ ), middle wealth status (AHR $=0.90,95 \% \mathrm{Cl}: 0.83,0.97$ ), and richest wealth status (AHR $=0.81,95 \% \mathrm{Cl}: 0.73,0.90)$ were significantly associated with lower hazards of underfive mortality. Whereas, advanced maternal age ( $\geq 35$ years) ( $A H R=1.13,95 \% \mathrm{Cl}: 1.04,1.24)$ " babies born to household who did not have media exposure (AHR $=1.13,95 \% \mathrm{Cl}: 1.07,1.20)$, twin births (AHR $=3.81,95 \% \mathrm{Cl}$ : 3.52 , 4.12), being male child (AHR $=1.27,95 \% \mathrm{Cl}: 1.21,1.33)$, small birth size at birth (AHR=1.73,95\% Cl: 1.63, 1.84), and large size at birth (AHR $=1.11,95 \% \mathrm{Cl}: 1.04,1.11)$ were significantly associated with higher hazards of under-five mortality.

\footnotetext{
* Correspondence: getayenehantehunegn@gmail.com

Department of Epidemiology and Biostatistics, institute of public health, College of medicine and health science, University of Gondar, Gondar, Ethiopia
}

C C The Author(s). 2021 Open Access This article is licensed under a Creative Commons Attribution 4.0 International License, which permits use, sharing, adaptation, distribution and reproduction in any medium or format, as long as you give appropriate credit to the original author(s) and the source, provide a link to the Creative Commons licence, and indicate if changes were made. The images or other third party material in this article are included in the article's Creative Commons licence, unless indicated otherwise in a credit line to the material. If material is not included in the article's Creative Commons licence and your intended use is not permitted by statutory regulation or exceeds the permitted use, you will need to obtain permission directly from the copyright holder. To view a copy of this licence, visit http://creativecommons.org/licenses/by/4.0/. The Creative Commons Public Domain Dedication waiver (http://creativecommons.org/publicdomain/zero/1.0/) applies to the data made available in this article, unless otherwise stated in a credit line to the data. 
Conclusion: Under-five mortality is a major public health concern in East African countries. Health facility delivery, ANC visit, higher wealth status, adequate birth spacing, wanted pregnancy, and maternal education were significantly correlated with a lower risk of under-5 mortality. Whereas, higher birth order, small or large size at birth, male birth, twin birth, advanced maternal age and mothers who didn't have media exposure were significantly correlated with a higher risk of under-five mortality. This study highlights that public health programs should enhance health facility delivery, ANC visit, media exposure, maternal education, and adequate birth spacing to decrease the incidence of under-five mortality in East Africa.

Keywords: Under-five mortality, East Africa, Multilevel Weibull regression model

\section{Background}

According to the World Health Organization (WHO), under-five mortality is defined as the death of a child before reaching age five [1]. Despite the global progress in under-five mortality [2], East African countries continued to share the huge burden [3]. Reducing under-five mortality is included in the Sustainable Development Goals (SDGs) as an unfinished agenda of MDGs [4]. Despite the substantial decrement in the global underfive mortality rates from 90.6 per 1000 live births in 1990 to 42.5 per 1000 live births in 2015 [5], an estimated 5.3 million children under age five still died annually [6].

The burden of under-five mortality is unevenly distributed across, it is highly concentrated in middle-income and low-income countries [7, 8]. Public health interventions such as Expanded Program of Immunization (EPI) $[9,10]$, exclusively breastfeeding practice for 6 months [11], and maternal health service utilization [12] such as Antenatal Care (ANC) visit, Postnatal Care (PNC) visit and health facility delivery are the basic strategies implemented by many African countries to reduce under-five mortality $[13,14]$.

The leading causes of under-five mortality in SSA are diarrheal disease [15], malnutrition [16], pneumonia [17], malaria [18], prematurity [19], and neonatal sepsis [20] which are preventable and treatable. Previous studies revealed that residence [21, 22], maternal education [23], husband education [24], marital status [25], sex of child [26], ANC visit [27], PNC [28], place of delivery [29], preceding birth interval [30], twin births [13], parity [31], maternal age [32], media exposure [33], wealth status [13], child nutritional status [34], mode of delivery $[21,35,36]$ and women decision making autonomy [25] as significant predictors of under-five mortality.

Though there are studies reported in several East African countries [29, 37-42], they are unable to capture the incidence and predictors of the level of East African Region. Investigating the inter-country variation in the incidence of under-five mortality and the pooled incidence of under-five mortality at the East Africa level is important for prioritization to design public health interventions. Besides, this study was based on the weighted pooled DHS data of 12 East African countries that have adequate power to detect the true effect of the predictors on under-five mortality using multilevel survival analysis.

\section{Methods \\ Data source}

This study was based on the DHS data of 12 East African countries conducted from 2008 to 2019. DHS is a community-based cross-sectional study conducted every five-year to generate updated health and healthrelated indicators. The DHS conducted in Burundi, Ethiopia, Comoros, Uganda, Rwanda, Tanzania, Mozambique, Madagascar, Zimbabwe, Kenya, Zambia, and Malawi were appended together to determine the incidence and predictors of under-five mortality in East Africa. Each country's survey consists of different datasets including men, women, children, birth, and household datasets; for this study, we used the Kids Record (KR) file. In the KR file, all mothers with under-five children born in the last 5 years preceding the survey were included. In DHS, a two-stage stratified cluster sampling technique was employed using the Population and Housing Census (PHC) as a sampling frame. In the first stage, Enumeration Areas (EAs) were chosen with probability sampling proportional to the size of the EAs with independent selection in each sampling stratum. In the second stage, households were systematically selected. The detailed sampling procedure was presented in the full DHS report. A total weighted sample of 138,803 live births was included in the study.

\section{Variables of the study}

The dependent variable was under-five mortality. A child who has died within 5 years of birth was considered as an event and those who were alive during the study period were considered as censored. Under- 5 mortality is defined as the death of live birth within 59 months of life. Age at death was recorded in months. Given the hierarchical nature of DHS data, independent variables considered for this study were from two sources (individual-level and community-level variables). The individual-level independent variables were 
maternal education, maternal age, husband education, wealth status, media exposure, marital status, maternal occupation, child age, sex of child, birth order, birth size, birth outcome, birth size, place of delivery, mode of delivery, women health care decision making autonomy, unwanted pregnancy, number of ANC visit and preceding birth interval. The community-level variables were the place of residence, country, and distance to the health facility.

\section{Data management and analysis}

The data were weighted using sampling weight, primary sampling unit, and strata before any statistical analysis to restore the representativeness of the survey and to account for the sampling design to get reliable statistical estimates. The sampling statisticians determine how many samples are needed in each stratum to get reliable estimates, in DHS, some areas were oversampled, and some areas were under-sampled. So, to get statistics that are representative of the country, the distribution of under-5 children in the sample need to be weighted (mathematically adjusted) such that it resembles the true distribution in East Africa by using sampling weight (v005), primary sampling unit (v021) and strata (v022). The descriptive and summary statistics were conducted using STATA version 14 software. The DHS data has a hierarchical structure, and therefore under-5 children were nested within a cluster/EAs. This violates the traditional regression model assumption, which is the independence of observations and equal variance across clusters. The Proportional Hazard (PH) assumption was assessed using global schoenfeld residual test and it was violated $(p$-value< 0.05$)$, and therefore, the coxproportional model was not the appropriate model for the data. To check whether there was clustering or not using Variance Partition Coefficient (VPC), it showed that there was clustering that should be considered using multilevel survival models to get a reliable estimate. For model selection; log-likelihood ratio test, deviance (-2LL), Akaike Information Criteria (AIC), and CoxSnell residual plot were applied. A Cox-Snell residual plot considers the distribution and estimated parameters from the lifetime regression model, and the plot of the Weibull regression model was closer to the bisector than the others. Besides, the multilevel Weibull regression model was the best-fitted model as it had the lowest deviance, $\mathrm{AIC}$, and $\mathrm{BIC}$ values.

Weibull regression is the most popular parametric model, as it is highly flexible and has simple hazard and survival functions $[43,44]$. It provides estimates of the baseline hazard function. Which is characterized by two parameters: one is the shape parameter denoted by $\gamma$ and the other is the scale parameter denoted by $\lambda$. It is noted that when $\gamma=1$, the hazard rate remains constant over time and the distribution turns exponential. The hazard rate increases when $\gamma>1$ and decreases when $\gamma<1$ lover the lifetimes. As a result, Weibull distribution could be used to model the survival distribution of a population that has either increasing or decreasing or constant risk. Besides, we have checked the distribution of the data follows a Weibull distribution or not by plotting the logarithm of survival function against times, and the logarithm of the survival function decreases sharply from 0 to as time increases. Therefore, variables with a $p$-value less than 0.20 in the bivariable multilevel Weibull regression were included in the multivariable analysis. In the multivariable analysis, the Adjusted Hazard Ratio (AHR) with 95\% Confidence Interval (CI) was used to declare significant predictors of under-five mortality.

\section{Ethical consideration}

Permission for data access was obtained from the measure DHS program through an online request from http://www.dhsprogram.com. The data used for this study were publicly available with no personal identifier.

\section{Result}

Socio-demographic and economic characteristics of study participants

Of the total 138,803 under-five children, about 19,563 (14.1\%) were from Kenya, and 3235 (2.3\%) were from Comoros. More than three-fourths $(78.3 \%)$ of children's mothers were rural residents. About 66,070 (47.6\%) of their mother were aged 25-34 years and 73,811 (53.2\%) of the mothers attained primary education (Table 1).

\section{Maternal obstetric and child-related characteristics}

The majority (56.5\%) of the children were aged 12-36 months and about $50.6 \%$ were females. Nearly threefourths $(72.6 \%)$ of the children were born at the health facility and 4415 (3.2\%) were multiple births (Table 2).

\section{Incidence of under-five mortality}

The under-five mortality rate in East Africa was 51.318 (95\% CI: 51.311, 51.323) per 1000 live births, ranged from 38.608 (95\% CI: 38.605, 38.615) per 1000 live births in Rwanda to 74.333 (95\% CI: 74.332, 74.341) to 1000 live births in Mozambique (Fig. 1). The overall KaplanMeier failure curve indicated that the probability of under-five mortality increased over time. The risk of dying was increased alarmingly in the first year of life and slowly to aged 3 years and then it remains steady (Fig. 2). The log-rank test showed that there was a significant difference in under-five mortality probability across the residence, country, mode of delivery, birth order, ANC, birth outcome, place of delivery, preceding birth interval, health insurance coverage, distance to the health facility, wanted pregnancy, birth size, maternal 
Table 1 The socio-demographic and economic characteristics of the study participants in East Africa

\begin{tabular}{|c|c|c|}
\hline Variable & Weighted frequency $(N=138,803)$ & Percentage (\%) \\
\hline \multicolumn{3}{|l|}{ Country } \\
\hline Burundi & 13,611 & 9.8 \\
\hline Ethiopia & 11,022 & 7.9 \\
\hline Kenya & 19,563 & 14.1 \\
\hline Comoros & 3235 & 2.3 \\
\hline Madagascar & 12,686 & 9.1 \\
\hline Malawi & 17,395 & 12.5 \\
\hline Mozambique & 11,704 & 8.4 \\
\hline Rwanda & 8003 & 5.8 \\
\hline Tanzania & 10,052 & 7.2 \\
\hline Uganda & 15,270 & 11.0 \\
\hline Zambia & 9841 & 7.1 \\
\hline Zimbabwe & 6418 & 4.6 \\
\hline \multicolumn{3}{|l|}{ Residence } \\
\hline Rural & 30,108 & 21.7 \\
\hline Urban & 108,695 & 78.3 \\
\hline \multicolumn{3}{|l|}{ Maternal age } \\
\hline $15-24$ & 41,683 & 30.0 \\
\hline $25-34$ & 66,070 & 47.6 \\
\hline$\geq 35$ & 31,050 & 22.4 \\
\hline \multicolumn{3}{|l|}{ Maternal education status } \\
\hline No & 33,448 & 24.1 \\
\hline Primary & 73,811 & 53.2 \\
\hline Secondary and above & 31,544 & 22.7 \\
\hline \multicolumn{3}{|l|}{ Husband education status } \\
\hline No & 22,654 & 16.3 \\
\hline Primary & 57,352 & 41.3 \\
\hline Secondary and above & 58,797 & 42.4 \\
\hline \multicolumn{3}{|l|}{ Wealth status } \\
\hline Poorest & 33,229 & 23.9 \\
\hline Poorer & 29,866 & 21.5 \\
\hline Middle & 26,820 & 19.3 \\
\hline Richer & 25,590 & 18.4 \\
\hline Richest & 23,298 & 16.8 \\
\hline \multicolumn{3}{|l|}{ Media exposure } \\
\hline No & 48,776 & 35.1 \\
\hline Yes & 90,027 & 64.9 \\
\hline \multicolumn{3}{|l|}{ Marital status } \\
\hline Single & 6482 & 4.7 \\
\hline Married & 118,613 & 85.4 \\
\hline Divorced/widowed/separated & 13,708 & 9.9 \\
\hline \multicolumn{3}{|l|}{ Respondent working } \\
\hline No & 44,616 & 32.1 \\
\hline Yes & 94,187 & 67.9 \\
\hline
\end{tabular}


Table 2 The maternal obstetric and child related characteristics of the study participants in East Africa

\begin{tabular}{|c|c|c|}
\hline Variables & Weighted frequency & Percentage (\%) \\
\hline \multicolumn{3}{|l|}{ Child age (in months) } \\
\hline$<12$ & 27,400 & 19.7 \\
\hline $12-36$ & 78,409 & 56.5 \\
\hline $37-60$ & 32,994 & 23.8 \\
\hline \multicolumn{3}{|l|}{ Sex of child } \\
\hline Male & 70,206 & 50.6 \\
\hline Female & 68,597 & 49.4 \\
\hline \multicolumn{3}{|l|}{ Birth outcome } \\
\hline Single & 134,388 & 96.8 \\
\hline Multiple & 4415 & 3.2 \\
\hline \multicolumn{3}{|l|}{ Birth size } \\
\hline Large & 40,812 & 29.4 \\
\hline Average & 64,315 & 46.3 \\
\hline Small & 33,676 & 24.3 \\
\hline \multicolumn{3}{|l|}{ Birth order } \\
\hline First & 32,654 & 23.5 \\
\hline $2-4$ & 66,883 & 48.2 \\
\hline$\geq 5$ & 39,266 & 28.3 \\
\hline \multicolumn{3}{|l|}{ Place of delivery } \\
\hline Home & 38,005 & 27.4 \\
\hline Health facility & 100,798 & 72.6 \\
\hline \multicolumn{3}{|l|}{ Mode of delivery } \\
\hline Vaginal & 130,518 & 94.0 \\
\hline Caesarean delivery & 8285 & 6.0 \\
\hline \multicolumn{3}{|c|}{ Women health care decision making autonomy } \\
\hline Respondent alone & 84,970 & 18.6 \\
\hline Jointly with their husband/parent & 55,653 & 40.1 \\
\hline Husband/parent alone & 57,402 & 41.3 \\
\hline \multicolumn{3}{|l|}{ Distance to health facility } \\
\hline A big problem & 84,970 & 61.2 \\
\hline Not a big problem & 53,833 & 38.8 \\
\hline \multicolumn{3}{|l|}{ Unwanted pregnancy } \\
\hline No & 82,691 & 59.6 \\
\hline Yes & 56,112 & 40.4 \\
\hline \multicolumn{3}{|l|}{ Number of ANC visit } \\
\hline No & 6127 & 4.4 \\
\hline $1-3$ & 39,791 & 28.7 \\
\hline$\geq 4$ & 92,885 & 66.9 \\
\hline \multicolumn{3}{|l|}{ Preceding birth interval (in months) } \\
\hline$<24$ & 18,963 & 13.7 \\
\hline $24-48$ & 58,591 & 42.2 \\
\hline$\geq 49$ & 61,249 & 44.1 \\
\hline
\end{tabular}


Table 2 The maternal obstetric and child related characteristics of the study participants in East Africa (Continued)

\begin{tabular}{|c|c|c|}
\hline Variables & Weighted frequency & Percentage (\%) \\
\hline \multicolumn{3}{|l|}{ Weight/age } \\
\hline Normal & 126,731 & 91.3 \\
\hline Moderately underweight & 9089 & 6.6 \\
\hline Severely underweight & 2983 & 2.2 \\
\hline \multicolumn{3}{|l|}{ Height/age } \\
\hline Normal & 107,654 & 77.6 \\
\hline Moderately stunted & 19,032 & 13.7 \\
\hline Severely stunted & 12,117 & 8.7 \\
\hline \multicolumn{3}{|l|}{ Weight/height } \\
\hline Normal & 134,523 & 96.9 \\
\hline Moderately wasted & 3044 & 2.2 \\
\hline Severely wasted & 1236 & 0.9 \\
\hline
\end{tabular}

education, husband education, respondent age, twin pregnancy, and wealth index (log-rank, $p<005)$ (Table 3). The $\mathrm{PH}$ assumption was violated (Global Schoenfeld residual test, $p<0.0001$ ), indicated that the Cox-proportional model was not an appropriate model (Table 4). Therefore, parametric models were fitted and the Weibull regression model was the best-fitted model (Table 5). Besides, in the null model, the VPC was 0.11 , which showed that about $11 \%$ of the total variability in under-five mortality was due to clustering. In addition, the LR-test was significant it indicates the multilevel Weibull regression model was the bestfitted model for the data. We have fitted four models and the final model was the best-fitted model since it had the lowest deviance (Table 6).

\section{Predictors of under-five mortality}

Maternal age, maternal education, media exposure, birth outcome, sex of the child, birth size, birth order, place of

\begin{tabular}{|c|c|c|c|c|}
\hline \multirow[b]{2}{*}{ Country } & \multirow[b]{2}{*}{ Died } & \multicolumn{2}{|c|}{ Pooled under-five mortality rate } & \multirow{2}{*}{$\begin{array}{l}\% \\
\text { Weight }\end{array}$} \\
\hline & & \multicolumn{2}{|c|}{ Pooled incidence } & \\
\hline Burundi & 797 & 13611 & $58.56(58.55,58.56)$ & 8.65 \\
\hline Ethiopia & 605 & 11022 & $54.89(54.89,54.89)$ & 7.44 \\
\hline Kenya & 861 & 19563 & $\div \quad 44.01(44.01,44.01)$ & 16.29 \\
\hline Comoros & 137 & 3235 & $42.35(42.34,42.36)$ & 2.79 \\
\hline Madagascar & 710 & 12686 & $55.97(55.96,55.97)$ & 8.41 \\
\hline Malawi & 846 & 17395 & $48.63(48.63,48.64)$ & 13.17 \\
\hline Mozambique & 870 & 11704 & $74.33(74.33,74.34)$ & 5.96 \\
\hline Rwanda & 309 & 8003 & * $38.61(38.61,38.61)$ & 7.55 \\
\hline Tanzania & 531 & 10052 & $52.83(52.82,52.83)$ & 7.04 \\
\hline Ugnada & 778 & 15270 & - $50.95(50.95,50.95)$ & 11.06 \\
\hline Zambia & 480 & 9841 & $48.78(48.77,48.78)$ & 7.43 \\
\hline Zimbabwe & 363 & 6418 & $56.56(56.55,56.57)$ & 4.21 \\
\hline \multicolumn{3}{|c|}{ Overall $(1-$ squared $=100.0 \%, p=0.000$} & $51.32(51.31,51.32)$ & 100.00 \\
\hline \multicolumn{5}{|c|}{$\begin{array}{llll}-74.3 & 0 & 74.3\end{array}$} \\
\hline \multicolumn{5}{|c|}{$\begin{array}{l}\text { Fig. } 1 \text { The forest plot of the pooled incidence of under-five } \\
\text { mortality in and across East African countries }\end{array}$} \\
\hline
\end{tabular}

delivery, number of ANC visits, preceding birth interval, wanted pregnancy, wealth, women autonomy and country were significant predictors of under-five mortality. Children born to mothers aged 35 years and above had 1.13 times (AHR $=1.13,95 \%$ CI: 1.04, 1.24) higher hazard of death in the first 5 years compared to a child born to a mother aged 15-24 years. A child born to a mother who attained secondary education and above had decreased risk of under-five mortality by $17 \%(\mathrm{AHR}=0.83$, $95 \%$ CI: $0.75,0.91)$ than a child born to a mother who had no formal education. A child born to a mother who had no media exposure was 1.13 times $(\mathrm{AHR}=1.13$, $95 \%: 1.07,1.20$ ) higher risk of under-five mortality than a child born to a mother who had media exposure. The hazard of under-five mortality among twin births was 3.81 times (AHR $=3.81,95 \%$ CI: 3.52, 4.12) higher than single births. Being male had an increased hazard of under-five mortality by $27 \%$ (AHR $=1.27,95 \% \mathrm{CI}: 1.21$, 1.33) than a female child. Children who were small and large size at birth had 1.73 times $(\mathrm{AHR}=1.73,95 \% \mathrm{CI}$ :

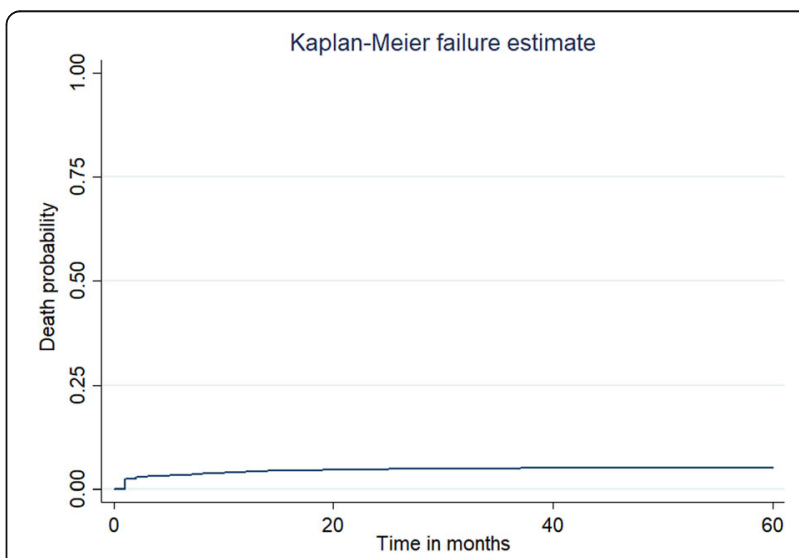

Fig. 2 The overall Kaplan-Meier curve of the survival status of under5 mortality in East Africa 
Table 3 Log rank test for the predictors of under-five mortality in East Africa

\begin{tabular}{llll}
\hline Variable & $\boldsymbol{p}$-value & Variable & $\boldsymbol{p}$-value \\
\hline Residence & $<0.0001$ & Mode of delivery & 0.03 \\
Country & $<0.0001$ & Media exposure & 0.14 \\
Covered by health insurance & $<0.0001$ & Maternal education & $<0.0001$ \\
Wealth index & $<0.0001$ & Husband education & $<0.0001$ \\
Birth outcome & $<0.0001$ & Wanted pregnancy & $<0.0001$ \\
Distance to health facility & $<0001$ & Women decision making autonomy & 0.005 \\
Place of delivery & $<0.0001$ & Maternal age & $<0.0001$ \\
ANC visit during pregnancy & $<0.0001$ & Birth order & $<0.0001$ \\
Birth interval & $<0.0001$ & Birth size & $<0.001$ \\
Sex of child & $<0.001$ & &
\end{tabular}

$1.63,1.84)$ and 1.11 times $(\mathrm{AHR}=1.11,95 \% \mathrm{CI}: 1.04$, 1.17) higher hazard of under-five mortality than average size baby at birth respectively.

The hazard of under-five mortality among second to fourth, and five and above birth order was decreased by $38 \%(\mathrm{AHR}=0.62,95 \% \mathrm{CI}: 0.56,0.67)$, and $32 \%(\mathrm{AHR}=$ $0.68,95 \%$ CI: $0.61,0.76)$ than first birth respectively. The hazard of under-five mortality among children born at a health facility was decreased by $13 \%$ (AHR $=0.87,95 \%$

Table 4 Schoenfeld residual test for checking proportional hazard assumption for the incidence of under-five mortality and its predictors among live births in the 12 East African countries

\begin{tabular}{lllll}
\hline Variables & Rho & Chi2 & Df & Prob $>$ chi2 \\
\hline Residence & 0.006 & 0.23 & 1 & 0.62 \\
Country & -0.022 & 3.54 & 1 & 0.06 \\
Wealth index & -0.04 & 12.48 & 1 & 0.0004 \\
Sex of child & 0.045 & 16.53 & 1 & $<0.001$ \\
Women education & -0.02 & 2.95 & 1 & 0.09 \\
Husband education & -0.034 & 8.53 & 1 & 0.004 \\
Place of delivery & -0.022 & 3.56 & 1 & 0.06 \\
ANC visit & 0.084 & 58.48 & 1 & $<0.001$ \\
Birth interval & -0.006 & 0.23 & 1 & 0.63 \\
Mode of delivery & -0.03 & 5.54 & 1 & 0.02 \\
Birth outcome & -0.08 & 42.99 & 1 & $<0.001$ \\
Maternal age & 0.04 & 13.76 & 1 & 0.0002 \\
Media exposure & -0.011 & 0.90 & 1 & 0.34 \\
Wanted pregnancy & 0.018 & 2.24 & 1 & 0.13 \\
Distance to health facility & -0.017 & 2.04 & 1 & 0.15 \\
Covered by health insurance & 0.0006 & 0.001 & 1 & 0.96 \\
Women autonomy & 0.0007 & 0.001 & 1 & 0.95 \\
Maternal age & 0.003 & 0.07 & 1 & 0.79 \\
Birth order & -0.0019 & 0.03 & 1 & 0.987 \\
Birth size & -0.093 & 71.41 & 1 & $<0.001$ \\
Global test & & 333.84 & 20 & $<0.0001$ \\
\hline
\end{tabular}

CI: $0.82,0.93)$ than those born at home. Children born to mothers who had 1-3 ANC visits during pregnancy had 0.61 times decreased hazard of mortality (AHR = 0.61, 95\% CI: $0.54,0.68)$ than a child born to a mother who didn't have ANC visit during pregnancy. Children who were born within 24-48 birth intervals had decreased hazard of mortality by $47 \%$ (AHR $=0.53,95 \%$ CI: $0.50,0.57)$ than a child born within 23 months of birth interval. Children who were wanted having decreased hazard of mortality within 5 years of birth by $28 \%$ $(\mathrm{AHR}=0.72, \quad 95 \%$ CI: $0.68,0.76)$ than unwanted childbirth.

The hazard of under-five mortality among child in the middle and richest household were decreased by $10 \%$ $(\mathrm{AHR}=0.90,95 \%$ CI: 0.83, 0.97) and $19 \%(\mathrm{AHR}=0.81$, $95 \%$ CI: $0.73,0.90)$ than child in the poorest household, respectively. Child in Burundi, Kenya, Comoros, Madagascar, Mozambique, and Zimbabwe were 1.23 times $(\mathrm{AHR}=1.23,95 \% \mathrm{CI}: 1.06,1.44), 0.79$ times $(\mathrm{AHR}=0.79,95 \% \mathrm{CI}: 0.68,0.91), 0.66$ times $(\mathrm{AHR}=$ 0.66, 95\% CI: 0.53, 0.83), 1.10 times $(\mathrm{AHR}=1.10,95 \%$ CI: $0.95,1.28), 1.42$ times $(\mathrm{AHR}=1.42,95 \% \mathrm{CI}: 1.21$, 1.66), and 1.20 times $(\mathrm{AHR}=1.20,95 \% \mathrm{CI}: 1.01,1.45)$ higher hazard of under-five mortality than child in Rwanda respectively (Table 6).

\section{Discussion}

Under-5 mortality is an important global public health issue particularly in Sub-Saharan Africa since it is commonly used as one of the most sensitive measures of

Table 5 Model comparison parameters

\begin{tabular}{llll}
\hline Parameter & Deviance & AIC & BIC \\
\hline Weibull regression & $84,122.42$ & $84,164.42$ & $84,371.03$ \\
exponential regression & $112,215.08$ & $112,255.1$ & $112,451.9$ \\
gamma regression & $99,804.58$ & $99,846.59$ & $100,053.2$ \\
lognormal regression & $99,575.74$ & $99,617.74$ & $99,824.35$ \\
log- logistic regression & $98,813.36$ & $98,855.35$ & $99,061.96$ \\
\hline
\end{tabular}


Table 6 The multilevel Weibull regression analysis of individual and community level predictors of under-five mortality in East Africa

\begin{tabular}{l} 
Variable Null \\
\hline Maternal age \\
$15-24$ \\
$25-34$ \\
$\geq 35$
\end{tabular}

Model 1 (AHR with 95\% Cl)
Model 2(AHR with 95\% Cl) Model 3 (AHR with 95\% Cl)

Maternal education status

No

Primary

Secondary and above

Husband education status

No

Primary

Secondary and

above

Media exposure

Yes

No

Birth outcome

$$
\text { Single }
$$

Multiple

\section{Sex of child}

Male

Female

Birth size

Average
small
Large

Birth order

First

2-4

$\geq 5$

Place of delivery

Home

Health facility

Mode of delivery

Vaginal

Caesarean section

Number of ANC visit

No visit

$1-3$

$\geq 4$

Preceding birth interval (in months)

$<24$

24-48

$\geq 49$

Wanted birth

No

Yes

\section{1}

$0.94(0.88,1.01)$

$1.13(1.03,1.23)$

1

$1.04(0.98,1.11)$

$0.81(0.74,0.88)$

$1.03(0.96,1.11)$

$1.00(0.92,1.08)$

1

$1.10(1.05,1.17)$

1

$3.87(3.57,4.18)$

$1.23(1.18,1.29)$

1

1

$1.69(1.60,1.79)$

$1.15(1.08,1.22)$

1

$0.61(0.56,0.67)$

$0.68(0.61,0.76)$

1

$0.95(0.90,1.01)$

1

$1.06(0.96,1.17)$

1

$0.61(0.54,0.68)$

$1.01(0.90,1.13)$

1

$0.54(0.51,0.58)$

$0.50(0.46,0.54)$

1

$0.68(0.65,0.72)$
1

$0.95(0.89,1.01)$

$1.13(1.04,1.24)^{*}$

$1.06(0.99,1.13)$

$0.83(0.75,0.91)^{*}$

1

$1.03(0.96,1.11)$

$1.03(0.95,1.12)$

1

$1.13(1.07,1.20)^{*}$

$3.81(3.52,4.12)^{*}$

$1.27(1.21,1.33)^{*}$

1

$1.73(1.63,1.84)^{*}$

$1.11(1.04,1.17)^{*}$

1

$0.62(0.56,0.67)^{*}$

$0.68(0.61,0.76)^{*}$

1

$0.87(0.82,0.93)^{*}$

1

$1.09(0.99,1.21)$

1

$0.61(0.54,0.68)^{*}$

$1.02(0.91,1.14)$

1

$0.53(0.50,0.57)^{*}$

$1.02(0.91,1.14)$

$0.72(0.68,0.76)^{*}$ 
Table 6 The multilevel Weibull regression analysis of individual and community level predictors of under-five mortality in East Africa (Continued)

\begin{tabular}{|c|c|c|c|c|}
\hline Variable & Null model & Model 1 (AHR with 95\% Cl) & Model 2(AHR with 95\% Cl) & Model 3 (AHR with $95 \% \mathrm{Cl}$ ) \\
\hline \multicolumn{5}{|c|}{ Wealth status } \\
\hline \multicolumn{2}{|l|}{ Poorest } & 1 & & 1 \\
\hline \multicolumn{2}{|l|}{ Poorer } & $0.98(0.91,1.04)$ & & $0.95(0.89,1.02)$ \\
\hline \multicolumn{2}{|l|}{ Middle } & $0.93(0.86,1.01)$ & & $0.90(0.83,0.97)^{*}$ \\
\hline \multicolumn{2}{|l|}{ Richer } & $0.99(0.91,1.06)$ & & $0.93(0.86,1.01)$ \\
\hline \multicolumn{2}{|l|}{ Richest } & $0.89(0.82,0.98)$ & & $0.81(0.73,0.90)^{*}$ \\
\hline \multicolumn{5}{|c|}{ Women health care decision making autonomy } \\
\hline \multicolumn{2}{|c|}{ Respondent alone } & 1 & & 1 \\
\hline \multicolumn{2}{|c|}{$\begin{array}{l}\text { Jointly with } \\
\text { husband/partner }\end{array}$} & $1.07(1.01,1.15)$ & & $1.06(0.99,1.14)$ \\
\hline \multicolumn{2}{|c|}{$\begin{array}{l}\text { Husband/partner } \\
\text { alone }\end{array}$} & $1.13(1.06,1.21)$ & & $1.15(1.07,1.23)^{*}$ \\
\hline \multicolumn{5}{|l|}{ Residence } \\
\hline \multicolumn{2}{|l|}{ Rural } & & $1.12(1.05,1.18)$ & $0.95(0.89,1.03)$ \\
\hline \multicolumn{2}{|l|}{ Urban } & & 1 & 1 \\
\hline \multicolumn{5}{|l|}{ Country } \\
\hline \multicolumn{2}{|l|}{ Rwanda } & & 1 & 1 \\
\hline \multicolumn{2}{|l|}{ Burundi } & & $1.43(1.25,1.64)$ & $1.23(1.06,1.44)^{*}$ \\
\hline \multicolumn{2}{|l|}{ Ethiopia } & & $1.57(1.37,1.81)$ & $1.01(0.84,1.19)$ \\
\hline \multicolumn{2}{|l|}{ Kenya } & & $1.12(0.98,1.28)$ & $0.79(0.68,0.91)^{*}$ \\
\hline \multicolumn{2}{|l|}{ Comoros } & & $1.08(0.87,1.33)$ & $0.66(0.53,0.83)^{*}$ \\
\hline \multicolumn{2}{|c|}{ Madagascar } & & $1.49(1.30,1.71)$ & $1.10(0.95,1.28)^{*}$ \\
\hline \multicolumn{2}{|l|}{ Malawi } & & $1.25(1.09,1.49)$ & $1.07(0.91,1.25)$ \\
\hline \multicolumn{2}{|c|}{ Mozambique } & & $1.97(1.73,2.26)$ & $1.42(1.21,1.66)^{*}$ \\
\hline \multicolumn{2}{|l|}{ Tanzania } & & $1.35(1.17,1.55)$ & $1.01(0.86,1.20)$ \\
\hline \multicolumn{2}{|l|}{ Uganda } & & $1.38(1.21,1.57)$ & $0.98(0.84,1.16)$ \\
\hline \multicolumn{2}{|l|}{ Zambia } & & $1.27(1.11,1.47)$ & $1.02(0.86,1.22)$ \\
\hline \multicolumn{2}{|l|}{ Zimbabwe } & & $1.43(1.22,1.68)$ & $1.20(1.01,1.45)^{*}$ \\
\hline \multicolumn{5}{|c|}{ Distance to health facility } \\
\hline \multicolumn{2}{|c|}{ Not a big problem } & & 1 & 1 \\
\hline \multicolumn{2}{|c|}{ A big problem } & & $1.03(0.98,1.09)$ & $0.98(0.93,1.03)$ \\
\hline VPC & 0.11 & 0.08 & 0.09 & 0.07 \\
\hline LR test & $\begin{array}{l}\text { LR test vs. Weibull model: } \\
\text { chibar2(01) }=27.11 \text { Prob }>= \\
\text { chibar } 2=0.0000\end{array}$ & $\begin{array}{l}\text { LR test vs. Weibull model: } \\
\text { chibar2 }(01)=20.46 \text { Prob }>= \\
\text { chibar2 }=0.0000\end{array}$ & $\begin{array}{l}\text { LR test vs. Weibull model: } \\
\text { chibar2 }(01)=22.93 \text { Prob }>= \\
\text { chibar2 }=0.0000\end{array}$ & $\begin{array}{l}\text { LR test vs. Weibull model: } \\
\text { chibar2 }(01)=17.87 \text { Prob }>= \\
\text { chibar2 }=0.0000\end{array}$ \\
\hline Deviance & $85,876.04$ & $83,370.89$ & $85,648.85$ & $83,211.55$ \\
\hline
\end{tabular}

* $P$-value $<0.05, * * p$-value $<0.01, A N C$ Antenatal Care, VPC Variance Partition Coefficient, LR Likelihood Ratio

countries' well-being and development. Newborns and children have improved substantially over the last three decades even though the targeted two-thirds reduction was not achieved in East Africa. The incidence of neonatal mortality rate in East Africa was 51.32 (95\% CI: $51.31,51.32$ ) per 1000 live births, and significantly varied across the East African countries. It was higher than the SDG target for child mortality to reduce under-5 mortality of at least as low as 25 deaths per 1000 live births [45]. It could be due to lack of access to healthcare facilities, improper hygiene and sanitation, unclean water and continued risk of malnutrition in East African countries contributes to the huge burden of under-five mortality [46]. Besides, many of the African countries are continued to be prone to the leading causes of infectious diseases such as pneumonia, malaria, and diarrheal diseases that are closely linked to poverty [47, 48].

In this study maternal age, maternal education, media exposure, birth outcome, sex of the child, birth size, birth order, place of delivery, number of ANC visits, preceding birth interval, wanted pregnancy, wealth status, and women autonomy were significant predictors of 
under-five mortality. Maternal age was the important predictor of under-5 mortality in East Africa, children born to mothers aged 35 years and above had a higher risk of under-5 mortality than children born to mothers aged 15-24 years. It was consistent with studies reported in Nigeria [49], and SSA [21, 50], it could be due to children born to advance age mothers are at higher risk of low birth weight, prematurity, a congenital abnormality such as down syndrome, and malnutrition, this might be the possible reason for the increased risk of under- 5 mortality among births to advanced age mothers [51]. Maternal education and media exposure were significant predictors of under-5 mortality. It was in line with study findings in SSA [23], India [52], Nigeria [33], and Ghana [13], this might be because maternal education and media exposure are the most powerful tool in reducing under-five mortality [53]. Educated mothers and mothers who have media exposure are more likely to use information more effectively when caring for children and tend to seek appropriate health care more effectively than mothers who are not educated [54, 55]. Besides, educated mothers are more aware of the importance of childhood vaccination and basic child health care services. This could reduce the risk of under-five mortality [56]. Health facility delivery and ANC visit were significant predictors of decreased risk of under- 5 mortality. It was consistent with studies reported in Nigeria [57], and SSA [21, 58], it is since ANC visit during pregnancy and health facility delivery has a direct effect through prevention of infection, birth trauma, asphyxia and to rapidly detect and treat the complications [59]. Furthermore, ANC visit and health facility delivery is the entry point for the utilization of basic children health care services such as PNC visit, and childhood vaccination that could prevent the leading causes of under-5 mortality like pneumonia, malaria, and diarrheal diseases. This might be the possible explanation for the decreased risk of under-five mortality [60]. Male children were at increased risk of under-five mortality, this was supported by previous studies reported in India [61] and Iraq [62]. The excess risk of mortality among male children has been because the male sex is more vulnerable to morbidities such as low Apgar score, Intra-uterine Growth Restriction (IUGR), respiratory insufficiency, and prematurity than female sex [63]. As well, there is a hormonal difference among males and females, that males have a higher level of testosterone that has an association with pulmonary biomechanics and vascular development that could make males more vulnerable to respiratory and neurological diseases [64, 65]. Twin births were at higher risk of under-5 mortality than singletons. This was consistent study findings in Ethiopia [66], Burkina Faso [67], and Jordan [68], the excess risk of under-5 mortality among twin births is due to twin births are more likely to be born prematurely, to have intrauterine growth restriction, to be of lower birth weight, to have congenital abnormalities and to have complications around the time of labor and delivery, such as umbilical cord prolapse or premature separation of the placenta than singletons this might be the possible justifications [69, 70]. Having a preceding birth interval of 24-48 months had decreased the hazard of under-5 mortality than less than 24 months of birth interval. This was consistent with prior findings reported in developing countries [30, 71], the possible explanation could be due to the reason that mothers having shorter preceding birth intervals are less able to provide nourishment for the fetus because her body has less time to recuperate from the previous pregnancy. In addition, the uterus had less time to recover, and also lactation will deplete maternal nutrition [72] this could result in low birth weight, child malnutrition, lack of care, attention, and competition of children that could increase the risk of under- 5 mortality. Children who were a small size or large size at birth had a higher hazard of under-five mortality than children who were average size at birth, it could be due to low birth weight babies and macrosomic babies have immaturity of organs and underlined medical conditions like congenital heart diseases, down syndrome, HIV/AIDS, and Diabetic Mellitus (DM) that might increase their risk of mortality within 5 years of life. Birth order has a significant influence on the hazard of under- 5 mortality. Under- 5 mortality was highest in the first birth, it was consistent with studies reported in Nigeria [49] and India [53]. The possible explanation is that the first birth has increased susceptibility to pregnancy-related complications such as Antepartum Haemorrhage (APH), preeclampsia, prematurity, and fetal distress that could increase their risk of mortality before their fifth birthday. Wealth inequality and women's autonomy in health care decision-making had a significant effect on child survival, it was consistent with Bangladesh [73] and Ghana [74]. Under-5 mortality is highly concentrated in developing countries and is considered an indicator of the country's poverty level $[74,75]$. Children from wealthier households might have good nutrition and childhood health care services such as vaccination service, sunlight exposure, and good breastfeeding practices [76]. Unwanted births had a higher risk of under-five mortality than wanted births, this was supported by previous studies reported in Tanzania [42], it could be due to unwanted births may not have got adequate nutrition and basic childhood services.

This study has several strengths. First, the study was based on pooled weighted nationally representative DHS surveys of 12 East African countries that were weighted to make the resulting representative and to get a reliable 
estimate. Secondly, multilevel survival analysis was fitted by considering the hierarchical nature of the DHS data to get identify community and individual-level predictors of under-5 mortality. Furthermore, the study was based on the large sample size, this could increase the power of the study to get the true effect of the predictors. This finding should be interpreted in light of the following limitations. First, this study was based upon recall by mothers and it is prone to recall bias. Second, the pooled incidence of under-five mortality has considerable heterogeneity across countries $\left(\mathrm{I}^{2}<0.05\right)$, and we tried to identify the source of heterogeneity through metaregression and sub-group analysis but this was not significant. Furthermore, variables such as underlined medical conditions such as congenital heart diseases, pneumonia, malaria, etc. were not included in this study since these variables were not collected in DHS. Moreover, the DHS survey year was not the same in all countries, it was based on DHS conducted 2008 to 2019. This might overestimate or underestimate the incidence of under-five mortality.

\section{Policy implications}

Globally, evidence on the incidence and predictors of under-five mortality has grown substantially currently. This information has been used as a preventive measure that is linked to maternal and child health. From a policy point of view, the interventions which are designed to tackle under-five mortality such as childhood vaccination, health facility delivery, periodic child growth monitoring, exclusive breastfeeding practice, and maternal education should be scaled to sustain the reduction in under-five mortality in East African countries. Maternal education is central to improve birth spacing, childhood mortality, and morbidity. Enhancing the availability of education to women is needed to increases the chance of child survival as they adhered to the maternal and child health guidelines and recommendations.

\section{Conclusion}

Under-five mortality remains the major public health problem in East Africa which significantly varied across countries. The multilevel survival analysis demonstrated different individual and community level predictors that have a significant influence on under- 5 mortality. Advanced maternal age, twin births, low birth weight, macrosomia, and women who didn't participate in health care decision-making autonomy were significantly associated with an increased hazard of under-5 mortality. Whereas, maternal education, media exposure, higher order of birth, health facility delivery, having ANC visit, birth interval $\geq 24$ months, wanted pregnancy and rich wealth index were significantly associated with a lower risk of under-5 mortality. These findings are important to guide public health programs and interventions targeting enhancing health facility delivery, empowering women in making health care decision making, ANC visits, and birth space using family planning services to reduce the incidence of under-5 mortality in East Africa.

\section{Abbreviations \\ AHR: Adjusted hazard ratio; AIC: Akakie information criteria; ANC: Antenatal care; AHR: Adjusted hazard ratio; Cl: Confidence interval; DHS: Demographic health survey; DM: Diabetic mellitus; LLR: Log-likelihood ratio; \\ PH: Proportional hazard; PNC: Postnatal care; SDGs: Sustainable development goals; SSA: Sub-Saharan Africa; VPC: Variance partition coefficient; \\ WHO: World Health Organization}

\section{Acknowledgments}

We greatly acknowledge MEASURE DHS for granting access to the East African DHS data sets.

\section{Authors' contributions}

GAT, ABT, and ZTT conceived the study. GAT, ABT, and ZTT analyzed the data, drafted the manuscript, and reviewed the article. GAT, ABT and ZTT extensively reviewed the article. All authors read and approved the final manuscript.

\section{Funding}

No funding was obtained for this study.

Availability of data and materials

Data is available online and you can access it from www.measuredhs.com.

\section{Declarations}

\section{Ethical approval and consent to participate}

Since the study was a secondary data analysis of publically available survey data from the MEASURE DHS program, ethical approval and participant consent were not necessary for this particular study. We requested DHS Program and permission was granted to download and use the data for this study from http://www.dhsprogram.com. There are no names of individuals or household addresses in the data files.

Consent for publication

Not applicable since the study was a secondary data analysis.

\section{Competing interests}

Authors declare that they have no conflict of interest.

Received: 15 October 2020 Accepted: 1 November 2021

Published online: 12 November 2021

\section{References}

1. Ahmad OB, Lopez AD, Inoue M. The decline in child mortality: a reappraisal. Bull World Health Organ. 2000;78(10):1175-91.

2. Lim SS, Allen K, Bhutta ZA, Dandona L, Forouzanfar MH, Fullman N, et al. Measuring the health-related sustainable development goals in 188 countries: a baseline analysis from the global burden of disease study 2015. Lancet. 2016;388(10053):1813-50. https://doi.org/10.1016/S0140-6736(16)314 $67-2$.

3. Lozano R, Fullman N, Abate D, Abay SM, Abbafati C, Abbasi N, et al. Measuring progress from 1990 to 2017 and projecting attainment to 2030 of the health-related sustainable development goals for 195 countries and territories: a systematic analysis for the global burden of disease study 2017 Lancet. 2018;392(10159):2091-138. https://doi.org/10.1016/S0140-6736(1 8)32281-5.

4. Kumar S, Kumar N, Vivekadhish S. Millennium development goals (MDGS) to sustainable development goals (SDGS): addressing unfinished agenda and strengthening sustainable development and partnership. Indian J Commun Med. 2016;41(1):1-4. https://doi.org/10.4103/0970-0218.170955. 
5. Khodaee GH, Khademi G, Saeidi M. Under-five Mortality in the World (19002015). Int J Pediatr. 2015;3(6.1):1093-5.

6. Liu L, Oza S, Hogan D, Chu Y, Perin J, Zhu J, et al. Global, regional, and national causes of under-5 mortality in 2000-15: an updated systematic analysis with implications for the sustainable development goals. Lancet. 2016;388(10063):3027-35. https://doi.org/10.1016/S0140-6736(16)31593-8.

7. Kazembe L, Clarke A, Kandala N-B: Childhood mortality in sub-Saharan Africa: cross-sectional insight into small-scale geographical inequalities from Census data. BMJ Open 2012, 2(5), 2, 5, https://doi.org/10.1136/bmjopen-2 012-001421.

8. Wang H, Liddell CA, Coates MM, Mooney MD, Levitz CE, Schumacher AE, et al. Global, regional, and national levels of neonatal, infant, and under-5 mortality during 1990-2013: a systematic analysis for the global burden of disease study 2013. Lancet. 2014;384(9947):957-79. https://doi.org/10.1016/ S0140-6736(14)60497-9.

9. Ngowu R, Larson JS, Kim MS. Reducing child mortality in Nigeria: a case study of immunization and systemic factors. Soc Sci Med. 2008;67(1):161-4. https://doi.org/10.1016/j.socscimed.2008.03.004.

10. Duclos P, Okwo-Bele J-M, Gacic-Dobo M, Cherian T. Global immunization: status, progress, challenges and future. BMC Int Health Hum Rights. 2009; 9(S1):S2. https://doi.org/10.1186/1472-698X-9-S1-S2.

11. Azuine RE, Murray J, Alsafi N, Singh GK. Exclusive breastfeeding and underfive mortality, 2006-2014: a cross-national analysis of 57 low-and-middle income countries. Int J MCH AIDS. 2015;4(1):13-21. https://doi.org/10.21106/ ijma.52.

12. Rutherford ME, Mulholland K, Hill PC. How access to health care relates to under-five mortality in sub-Saharan Africa: systematic review. Tropical Med Int Health. 2010;15(5):508-19. https://doi.org/10.1111/j.1365-3156.2 010.02497.x.

13. Aheto JMK. Predictive model and determinants of under-five child mortality: evidence from the 2014 Ghana demographic and health survey. BMC Public Health. 2019;19(1):64. https://doi.org/10.1186/s12889-019-6390-4.

14. Seid AM, Yesuf ME, Koye DN. Prevalence of exclusive breastfeeding practices and associated factors among mothers in Bahir Dar city, Northwest Ethiopia: a community based cross-sectional study. Int Breastfeed J. 2013;8(1):14. https://doi.org/10.1186/1746-4358-8-14.

15. Nyamwaya BM. To establish the causes of under-five mortality at Kampala International University teaching hospital: Kampala International University, College of Medicine and Surgery; 2017.

16. Mose BN. Causes of under-five mortality at Kampala International University teaching hospital; 2013.

17. Mekonnen W, Assefa N, Asnake W, Sahile Z, Hailemariam D. Under five causes of death in Ethiopia between 1990 and 2016: Systematic review with meta-analysis. Ethiop J Health Dev (EJHD). 2020;34(2).

18. Adewemimo A, Kalter HD, Perin J, Koffi AK, Quinley J, Black RE. Direct estimates of cause-specific mortality fractions and rates of under-five deaths in the northern and southern regions of Nigeria by verbal autopsy interview. PLoS ONE. 2017;12(5):e0178129. https://doi.org/10.1371/journal. pone.0178129.

19. Xu Y-H, Huang X-W, Yang R-L. The under-five mortality rate and the causes of death in Zhejiang Province between 2000 and 2009. Zhongguo Dang Dai Er Ke Za Zhi. 2011;13(7):561-4.

20. Ntuli ST, Malangu N, Alberts M. Causes of deaths in children under-five years old at a tertiary hospital in Limpopo province of South Africa. Global J Health Sci. 2013;5(3):95-100. https://doi.org/10.5539/gihs.v5n3p95.

21. Yaya S, Bishwajit G, Okonofua F, Uthman OA. Under five mortality patterns and associated maternal risk factors in sub-Saharan Africa: a multi-country analysis. PLoS ONE. 2018;13(10):e0205977. https://doi.org/10.1371/journal. pone.0205977.

22. Sastry N. Urbanization, development and under-five mortality differentials by place of residence in São Paulo, Brazil, 1970-1991. Demogr Res. 2004;2: 355-86. https://doi.org/10.4054/DemRes.2004.S2.14.

23. Monden CW, Smits J. Maternal education is associated with reduced female disadvantages in under-five mortality in sub-Saharan Africa and southern Asia. Int J Epidemiol. 2013;42(1):211-8. https://doi.org/10.1093/ije/dys201.

24. Aly HY, Grabowski R. Education and child mortality in Egypt. World Dev. 1990;18(5):733-42. https://doi.org/10.1016/0305-750X(90)90021-O.

25. Kanmiki EW, Bawah AA, Agorinya I, Achana FS, Awoonor-Williams JK, Oduro $A R$, et al. Socio-economic and demographic determinants of under-five mortality in rural northern Ghana. BMC Int Health Hum Rights. 2014;14(1):24. https://doi.org/10.1186/1472-698X-14-24.
26. Costa JC, ICM d S, Victora CG. Gender bias in under-five mortality in low/ middle-income countries. BMJ Global Health. 2017;2(2).

27. Machio PM. Determinants of neonatal and under-five mortality in Kenya: do antenatal and skilled delivery care services matter? J Afr Dev. 2018;20(1):59-67.

28. Bosomprah S, Ragno PL, Gros C, Banskota H. Health insurance and maternal, newborn services utilisation and under-five mortality. Arch Public Health. 2015;73(1):51. https://doi.org/10.1186/s13690-015-0101-0.

29. Ettarh R, Kimani J. Determinants of under-five mortality in rural and urban Kenya. Rural Remote Health. 2012;12:1812.

30. Rutstein SO. Effects of preceding birth intervals on neonatal, infant and under-five years mortality and nutritional status in developing countries: evidence from the demographic and health surveys. Int I Gynecol Obstet. 2005;89:S7-S24. https://doi.org/10.1016/j.jigo.2004.11.012.

31. Kozuki N, Sonneveldt E, Walker N. Residual confounding explains the association between high parity and child mortality. BMC Public Health. 2013;13(3):1-8. https://doi.org/10.1186/1471-2458-13-S3-S5.

32. Sinha S, Aggarwal AR, Osmond C, Fall CH, Bhargava SK, Sachdev HS. Maternal age at childbirth and perinatal and under-five mortality in a prospective birth cohort from Delhi. Indian Pediatr. 2016;53(10):871-7. https://doi.org/10.1007/s13312-016-0950-9.

33. Adebowale SA, Morakinyo OM, Ana GR. Housing materials as predictors of under-five mortality in Nigeria: evidence from 2013 demographic and health survey. BMC Pediatr. 2017;17(1):30. https://doi.org/10.1186/s12887-01 6-0742-3.

34. Munthali T, Jacobs C, Sitali L, Dambe R, Michelo C. Mortality and morbidity patterns in under-five children with severe acute malnutrition (SAM) in Zambia: a five-year retrospective review of hospital-based records (20092013). Arch Public Health. 2015;73(1):23. https://doi.org/10.1186/s13690-0150072-1.

35. Wegbom Al, Essi ID, Kiri VA. Survival analysis of under-five mortality and its associated determinants in Nigeria: evidence from a survey data. Int I Stat Appl. 2019;9(2):59-66.

36. Mani K, Dwivedi SN, Pandey RM. Determinants of under-five mortality in rural empowered action group states in India: an application of cox frailty model. Int J MCH AIDS. 2012; (1):60-72. https://doi.org/10.21106/ijma.9.

37. Deribew A, Tessema F, Girma B. Determinants of under-five mortality in Gilgel gibe field research center, Southwest Ethiopia. Ethiop J Health Dev. 2007;21(2):117-24. https://doi.org/10.4314/ejhd.v21i2.10038.

38. Gebretsadik S, Gabreyohannes E. Determinants of under-five mortality in high mortality regions of Ethiopia: an analysis of the 2011 Ethiopia demographic and health survey data. Int J Popul Res. 2016:2016-7. https:// doi.org/10.1155/2016/1602761.

39. Diouf K, Tabatabai P, Rudolph J, Marx M. Diarrhoea prevalence in children under five years of age in rural Burundi: an assessment of social and behavioural factors at the household level. Glob Health Action. 2014;7(1): 24895. https://doi.org/10.3402/gha.v7.24895.

40. Hategeka C, Tuyisenge G, Bayingana C, Tuyisenge L. Effects of scaling up various community-level interventions on child mortality in Burundi, Kenya, Rwanda, Uganda and Tanzania: a modeling study. Global Health Res Policy. 2019;4(1):1. https://doi.org/10.1186/s41256-019-0106-2.

41. Mturi AJ, Curtis SL. The determinants of infant and child mortality in Tanzania. Health Policy Plan. 1995;10(4):384-94. https://doi.org/10.1093/hea pol/10.4.384.

42. Ogbo FA, Ezeh OK, Awosemo AO, Ifegwu IK, Tan L, Jessa E, et al. Determinants of trends in neonatal, post-neonatal, infant, child and underfive mortalities in Tanzania from 2004 to 2016. BMC Public Health. 2019; 19(1):1243. https://doi.org/10.1186/s12889-019-7547-x.

43. Royston P. Flexible parametric alternatives to the cox model, and more. Stata J. 2001;1(1):1-28. https://doi.org/10.1177/1536867X0100100101.

44. Bebbington M, Lai C-D, Zitikis R. A flexible Weibull extension. Reliab Eng Syst Saf. 2007;92(6):719-26. https://doi.org/10.1016/j.ress.2006.03.004

45. You D, Hug L, Ejdemyr S, Idele P, Hogan D, Mathers C, et al. Global, regional, and national levels and trends in under-5 mortality between 1990 and 2015, with scenario-based projections to 2030: a systematic analysis by the UN inter-agency Group for Child Mortality Estimation. Lancet. 2015; 386(10010):2275-86. https://doi.org/10.1016/50140-6736(15)00120-8.

46. Prüss-Ustün A, Wolf J, Bartram J, Clasen T, Cumming O, Freeman MC, et al. Burden of disease from inadequate water, sanitation and hygiene for selected adverse health outcomes: an updated analysis with a focus on low-and middle-income countries. Int J Hyg Environ Health. 2019;222(5): 765-77. https://doi.org/10.1016/j.ijheh.2019.05.004. 
47. Kent MM, Yin S. Controlling infectious diseases. Popul Bulletin-Washington. 2006;61(2).

48. Walker CLF, Rudan I, Liu L, Nair H, Theodoratou E, Bhutta ZA, et al. Global burden of childhood pneumonia and diarrhoea. Lancet. 2013;381(9875): 1405-16. https://doi.org/10.1016/S0140-6736(13)60222-6.

49. Kayode GA, Adekanmbi VT, Uthman OA. Risk factors and a predictive mode for under-five mortality in Nigeria: evidence from Nigeria demographic and health survey. BMC Pregnancy Childbirth. 2012;12(1):10. https://doi.org/10.11 86/1471-2393-12-10

50. Yaya S, Uthman OA, Okonofua F, Bishwajit G. Decomposing the rural-urban gap in the factors of under-five mortality in sub-Saharan Africa? Evidence from 35 countries. BMC Public Health. 2019;19(1):616. https://doi.org/10.11 86/s12889-019-6940-9.

51. Lozano R, Naghavi M, Foreman K, Lim S, Shibuya K, Aboyans V, et al. Global and regional mortality from 235 causes of death for 20 age groups in 1990 and 2010: a systematic analysis for the global burden of disease study 2010. Lancet. 2012;380(9859):2095-128. https://doi.org/10.1016/S0140-6736(12)61728-0.

52. Mandal S, Paul P, Chouhan P. Impact of maternal education on under-five mortality of children in India: insights from the National Family Health Survey, 2005-2006 and 2015-2016. Death Stud. 2019;(10):1-7. https://doi. org/10.1080/07481187.2019.1692970.

53. Singh $R$, Tripathi V. Maternal factors contributing to under-five mortality at birth order 1 to 5 in India: a comprehensive multivariate study. Springerplus. 2013;2(1):284. https://doi.org/10.1186/2193-1801-2-284.

54. Andriano L, Monden CW. The causal effect of maternal education on child mortality: evidence from a quasi-experiment in Malawi and Uganda. Demography. 2019;56(5):1765-90. https://doi.org/10.1007/s13524-01900812-3.

55. Muhuri PK. Health programs, maternal education, and differential child mortality in Matlab, Bangladesh. Popul Dev Rev. 1995;21(4):813-34. https:// doi.org/10.2307/2137775.

56. Ibnouf $A$, Van den Borne $H$, Maarse J. Factors influencing immunisation coverage among children under five years of age in Khartoum State, Sudan. S Afr Fam Pract. 2007;49(8):14-14f.

57. Ezeh OK, Agho KE, Dibley MJ, Hall JJ, Page AN. Risk factors for postneonatal, infant, child and under-5 mortality in Nigeria: a pooled cross-sectional analysis. BMJ Open. 2015;5(3):e006779. https://doi.org/10.1136/bmjopen-2 014-006779.

58. Doctor HV, Nkhana-Salimu S, Abdulsalam-Anibilowo M. Health facility delivery in sub-Saharan Africa: successes, challenges, and implications for the 2030 development agenda. BMC Public Health. 2018;18(1):765. https:// doi.org/10.1186/s12889-018-5695-z.

59. Lawn J, Kerber K, Enweronu-Laryea C, Massee Bateman O. Newborn survival in low resource settings - are we delivering? BJOG Int J Obstet Gynaecol. 2009;116:49-59. https://doi.org/10.1111/j.1471-0528.2009.02328.x.

60. Gilmore B, McAuliffe E. Effectiveness of community health workers delivering preventive interventions for maternal and child health in low-and middle-income countries: a systematic review. BMC Public Health. 2013; 13(1):847. https://doi.org/10.1186/1471-2458-13-847.

61. Sahu D, Nair S, Singh L, Gulati B, Pandey A. Levels, trends \& predictors of infant \& child mortality among scheduled tribes in rural India. Indian J Med Res. 2015;141(5):709-19. https://doi.org/10.4103/0971-5916.159593.

62. Awqati NA, Ali MM, Al-Ward NJ, Majeed FA, Salman K, Al-Alak M, et al. Causes and differentials of childhood mortality in Iraq. BMC Pediatr. 2009; 9(1):40. https://doi.org/10.1186/1471-2431-9-40

63. Ergaz Z, Avgil M, Ornoy A. Intrauterine growth restriction-etiology and consequences: what do we know about the human situation and experimental animal models? Reprod Toxicol. 2005;20(3):301-22. https://doi. org/10.1016/j.reprotox.2005.04.007.

64. Orshal JM, Khalil RA. Gender, sex hormones, and vascular tone. Am J Phys Regul Integr Comp Phys. 2004;286(2):R233-49. https://doi.org/10.1152/a jpregu.00338.2003.

65. Zhao D, Zou L, Lei X, Zhang Y. Gender differences in infant mortality and neonatal morbidity in mixed-gender twins. Sci Rep. 2017;7(1):1-6. https:// doi.org/10.1038/s41598-017-08951-6.

66. Dejene T, Girma E. Social determinants of under-five mortality in Ethiopia: event history analysis using evidence from Ethiopian demographic and health survey (EDHS); 2013. https://doi.org/10.4236/health.2013.55115.

67. Becher $H$, Müller $O$, Jahn A, Gbangou A, Kynast-Wolf G, Kouyaté B. Risk factors of infant and child mortality in rural Burkina Faso. Bull World Health Organ. 2004;82(4):265-73.
68. Islam MM, Marium U. Twin births in Jordan: incidence, trends, risk factors and implications for under-five mortality: evidence from the 2012 Jordan population and family health survey. J Biosoc Sci. 2019;51(6):857-74. https:// doi.org/10.1017/S0021932019000154.

69. Chauhan SP, Scardo JA, Hayes E, Abuhamad AZ, Berghella V. Twins: prevalence, problems, and preterm births. Am J Obstet Gynecol. 2010; 203(4):305-15. https://doi.org/10.1016/j.ajog.2010.04.031.

70. Moise J, Laor A, Armon Y, Gur I, Gale R. The outcome of twin pregnancies after IVF. Hum Reprod (Oxford, England). 1998;13(6):1702-5.

71. Kozuki N, Walker N. Exploring the association between short/long preceding birth intervals and child mortality: using reference birth interval children of the same mother as comparison. BMC Public Health. 2013;13(S3):S6. https:// doi.org/10.1186/1471-2458-13-S3-S6.

72. DaVanzo J, Hale L, Razzaque A, Rahman M. Effects of interpregnancy interval and outcome of the preceding pregnancy on pregnancy outcomes in Matlab, Bangladesh. BJOG Int J Obstet Gynaecol. 2007;114(9):1079-87. https://doi.org/10.1111/j.1471-0528.2007.01338.x.

73. Yaya S, Bishwajit G. Burden of acute respiratory infections among under-five children in relation to household wealth and socioeconomic status in Bangladesh. Trop Med Infect Dis. 2019;4(1):36. https://doi.org/10.3390/ tropicalmed4010036.

74. Kumi-Kyereme A, Amo-Adjei J. Household wealth, residential status and the incidence of diarrhoea among children under-five years in Ghana. J Epidemiol Global Health. 2016;6(3):131-40. https://doi.org/10.1016/j.jegh.201 5.05.001.

75. Wagstaff A, Watanabe N. Socioeconomic inequalities in child malnutrition in the developing world: the World Bank; 1999. https://doi.org/10.1596/18139450-2434.

76. Black RE, Allen LH, Bhutta ZA, Caulfield LE, De Onis M, Ezzati M, et al. Maternal, group CUS: maternal and child undernutrition: global and regional exposures and health consequences. Lancet. 2008;371(9608):24360. https://doi.org/10.1016/S0140-6736(07)61690-0.

\section{Publisher's Note}

Springer Nature remains neutral with regard to jurisdictional claims in published maps and institutional affiliations.
Ready to submit your research? Choose BMC and benefit from:

- fast, convenient online submission

- thorough peer review by experienced researchers in your field

- rapid publication on acceptance

- support for research data, including large and complex data types

- gold Open Access which fosters wider collaboration and increased citations

- maximum visibility for your research: over $100 \mathrm{M}$ website views per year

At $\mathrm{BMC}$, research is always in progress.

Learn more biomedcentral.com/submission 